\title{
"Effects of Muscle Energy Technique with and without Functional Task Training on Pain and Disability in Sacroiliac Joint Dysfunction"
}

\author{
Sumaira Parveen \\ Clinical Physiotherapist, \\ Booston Physiotherapy and wellness clinic, Lahore, Pakistan, \\ 0332-7577009 \\ Maham Javaid \\ Lecturer, \\ Aziz Fatima Medical \& Dental College, Faisalabad, Pakistan, \\ 0336-6667318 (Corresponding author), \\ maham.javaid11111@gmail.com

\section{Prof. Dr Muhammad Salman Bashir \\ Professor,} \\ Riphah International University, Lahore, Pakistan, \\ 0300-7889857

\section{Hafiz Muhammad Uzair Asghar} \\ Lecturer, \\ The Physio College of Rehabilitation Sciences, Multan, Pakistan, \\ $0332-1666957$ \\ Maria Iqbal Khan \\ Women Medical Officer, \\ Rural Health Centre, Ladhana, Pakistan, \\ 0333-3850083 \\ DOI: $10.31364 / \mathrm{SCIRJ} / \mathrm{V} 9.110 .2021 . P 1021883$ \\ http://dx.doi.org/10.31364/SCIRJ/v9.i10.2021.P1021883
}

\section{ABSTRACT:}

\section{Introduction:}

Sacroiliac joint dysfunction is the root cause of lower back pain. Sacroiliac joint is true synovial joint and has complex relationship of sacrum to adjacent structures including vertebra, muscles and ligaments, therefore movement at this joint affect other one. However, pain related to SI joint is more specific to unilateral and extremely variable pain pattern as compare to facet mediated and disco-genic low back pain. The occurrence of sacroiliac joint is far more common and has multifactorial origin, associated with age, gender and pregnancy related reasons Pain related to SI joint dysfunction can either be acute and chronic. For the determination of SI joint dysfunction, various tests are used. Three out of five pain provocation test positive mean that subject has sacroiliac dysfunction.

www.scirj.org

(C) 2021, Scientific Research Journal 
The aim of this research is to find out the effects of muscle energy technique with and without functional task training on pain and disability in sacroiliac joint dysfunction.

\section{Methodology:}

Total forty subjects were recruited in study, divided into two groups. Group A treated with muscle energy technique (METs) while Group B received functional task training along with METs. Total duration of study was three weeks with 3 sessions per week. assessment was done before treatment and at the end of every week. For measuring the outcomes, Numeric Pain Rating Scale NPRS and Modified Oswestry Disability Index MODI scales were used.

\section{Results:}

Findings has proved that differences between two groups were found to be significant statistically $(p$-value $<0.05)$ and statistically significant findings were observed within group analysis (p-value <0.05) with respect to Numeric Pain Rating Score and Modified Oswestry Disability Index.

\section{Conclusion:}

Findings revealed that differences between two groups were found to be significant statistically (p-value <0.05) and statistically significant findings were observed within group analysis (p-value <0.05) with respect to Numeric Pain Rating Score and Modified Oswestry Disability Index.

Key words: Sacroiliac Joint Dysfunction, Muscle energy technique (METs), functional task training

\section{INTRODUCTION:}

Low back pain is most common in recent era with $90 \%$ individuals may once confront to it in their lives with per year cost of $\$ 5$ billion to $\$ 20$ billion, also leading up to $\$ 50$ billion annually that involves indirect expenditures. (1) However pain related to SI joint is more specific to unilateral and extremely variable pain pattern as compare to facet mediated and disco-genic low back pain. (2) The occurrence of sacroiliac joint is far more common and has multifactorial origin, associated with age, gender and pregnancy related reasons. (3) Sacroiliac joint is true synovial joint, SI joint does not function independently, and it consists of anterior and posterior segments which are true and syndesmosis in nature respectively. The syndesmosis part contains sacroiliac ligaments, hip abductors and piriformis (4) The ligaments related to SI joint had an impact on joint stability and transfer of weight from trunk to lower extremities (5) Biomechanics of sacroiliac joint involve complex three-dimensional motion with rotational component of 3 degree or less and translation component of $2 \mathrm{~mm}$ or less. These movements between sacrum and ilium are responsible for sacroiliac www.scirj.org

(C) 2021, Scientific Research Journal 
dysfunction.(6) Evidence was present to support the use of muscle energy technique in low back pain within 3 to 5 weeks and isolated functional strength training to core muscles (transverse abdominis and multifidus).It has been observed that significant reduction in sacroiliac dysfunction and pain in group after receiving METs (7) However Mulligan mobilization had superior effects than other with three sets of 30 oscillations in 10 days(8). In comparison to one-time thoracic METs to lengthening and strengthening of the muscles significant reduction of pain was observed in group received thoracic METs than conventional (9) METs had superior effect than conventional treatment in treating the sacroiliac joint dysfunction. (6)Stabilization exercise targeted the on deep abdominal muscles strengthening found effective in trunk stability (10) The segmental stabilization had superior effects over superficial strengthening for all variables (11) While core stability exercises with general exercises had greater improvement in pain and disability related to vertebral translation and rotation than the general exercises alone.(12)

As SI Joint dysfunction a major cause of LBP and Research showed that with focused activation and strengthening of transvers abdominis and multifidus played a vital role to reduce the recurrence of low back pain. Although muscle energy technique for three weeks significantly reduced the pain. Keeping that to mind, it was a dire need to find out the additive effect of functional task training isolated to transvers abdominis and multifidus along with muscle energy technique. It may reduce the treatment sessions and time for the utmost improvement and rehabilitation in patients with sacroiliac joint dysfunction. The study was conducted to check whether there is any difference exists muscle energy technique with/without functional task training for improving pain and disability in sacroiliac joint dysfunction.

\section{MATERIALS AND METHODS:}

\section{SUBJECTS:}

This Randomized clinical trial. (IRCT\# IRCT20191009045045N1). The study was conducted at Boston physiotherapy and wellness clinic, Lahore and Fatima Memorial Hospital Shadman Lahore. The study was completed within the duration of 6-months at the end of the approval of ethical committee of RCRS \& Allied Health Sciences. (REF\#.) the Sample size was 36 and was calculated by using software of $G$ power version 3.1.9.2 with $5 \%$ margin of error and 0.80 power of study by taking standard deviation \pm mean from previous research (13) Forty 40 patients were recruited by assuming $10 \%$ attrition rate with $t$ tests - Means: Difference calculated between two independent means (of two groups) Analysis: A group priori: Computer required sample size, Input: Tail $(s)=$ Two, Effect size $d=0.9676267$, a err prob $=0.05$, Power $(1-\beta$ err prob $)=0.80$, Allocation ratio N2/N1 $=1$, Output: Non-centrality parameter $\delta=2.9028801$, Critical $t=2.0322445, D f=34$, and Sample size group $1=18$ Sample size group $2=$ 18 and sample size total $(N)=36$. We included the Subjects between 18 to 35 year of age. (14)Subjects with history of recurrent LBP, with at least three out of five pain provocation tests of SIJD must be positive and having pain at the Fortin area. The subjects with radiating pain past the knee, Lumbar disc herniation, and Spinal deformities and any spinal surgery history were excluded. 
ISSN 2201-2796

Convenient sampling technique was used to collect data. The subjects were assigned randomly to two groups A and B having each group containing 18 subjects according to their number in computer generated table. After taking informed consent, the patient had completed Numeric Pain Rating Scale NPRS for pain \&Modified Oswestry Disability Index MODI for low back index as subjective measurements for outcomes.

Initial session involved the performance of subjective and objective examination. In Group A-The subjects received METs (Position of patient was in side-lying with treated leg uppermost. The therapist was in standing position facing towards the patient. It was asked to the patient to bends both legs and hooks the leg around therapist's lower lumbar area. First, therapist palpated the PSIS then, command was given to the patient to press (with twenty percent effort) into therapist's side with their leg (hip extension) and hold for 10 seconds. As the patient relaxed, the therapist applied 5 repetitions of posterior rotation at the SI joint to encourage the innominate to maintain its posterior position while placing their mobilizing hand at the PSIS. This whole procedure had been painfree and repeated 5 times In Group -B The subjects received functional task training along with Mets. Light dynamic functional task training involved lumbar stabilization exercises targeting the multifidus and transverse abdominus muscle on little unstable base of support. We divided the plan in weeks where in week 1, Thoracic flexion and extension with abdominal breathing (drawing in phenomenon), week 2, Anterior and posterior pelvic tilt with heel slides, hip horizontal abduction, leg slide from crook lying position and week 3 Sitting and balancing on wobble board, (hip extensions, lumbar extension, trunk extension was performed), walking on a foam while trying to maintain balance, stepping up on BOSU (Both sides up) ball). Each activity had been performed with one set of 10 repetitions. Both groups received common treatment included, Hip abductor and adductor sets Gluteal sets, Piriformis stretches, Pelvic rotations and Hip abduction Two sets of five repetitions were performed. Evaluation was done before treatment at the end of one week, at second week and at the end of third week. The outcome measures that are measured are pain, strength and range of motion. Pain was measured by SPADI on day 0 and week 6 pre and post treatment respectively.

Two sets of five repetitions had been performed. The patients had called on alternative days throughout the session. Evaluation was done before treatment at the end of one week, at second week and at the end of third week. Outcome were measure by using numeric pain rating scale NPS and modified oswestry disability index MODI scale.

www.scirj.org

(C) 2021, Scientific Research Journal

http://dx.doi.org/10.31364/SCIRJ/v9.i10.2021.P1021883

This publication is licensed under Creative Commons Attribution CC BY. 


\section{DATA ANALYSIS}

SPSS for Windows Software, version 20 was used to analyzed the data. Statistical significance was set at P =0.05. Shapiro -wilks test was done for the assessment of normality of data, it was decided that parametric test would be used within a group or between two groups. For the Descriptive Statistics and Frequency tables were designed to show summary of group measurements measured over time. For The Changes Between Groups Mixed Model ANOVA was used to show progress of two groups while independent ttest were applied for between group analysis at different time periods and Changes Within Groups Repetitive measurement ANOVA was applied to compare the changes within each group.

\section{RESULTS:}

The data related to socio-demographic status including age, weight, height and BMI, the mean age of participants in muscle energy group was $29.29 \pm 3.53$ years as compare to $28.41 \pm 4.12$ years in functional task training group. Similarly, the mean of participants height in muscle energy group was 1.619 0.090 meters compared to $1.628 \pm 0.091$ in functional task training group. (Table .No 1). 
Parametric tests were applied to contrast and compare the pre, mid and post-treatment values. The baseline values of NPRS and MODI in Muscle energy technique group were $7.88 \pm 1.05$ and $58.29 \pm 6.80$ respectively. At the end of first week of treatment, the mean NPRS value reduced up to $6.5294 \pm 1.007$ that further decreased to $5.5294 \pm 0.94$ and MODI scores were reduced up to 45.0588 \pm 7.013 and 35.1176 \pm 5.441 at the end of $2^{\text {nd }}$ and $3^{\text {rd }}$ week of treatment correspondingly. While in Functional Task Training group were NPRS and MODI Scores were $7.76 \pm 1.11$ and $60.88 \pm 5.93$ respectively. The post treatment values were $2.647 \pm 0.60$

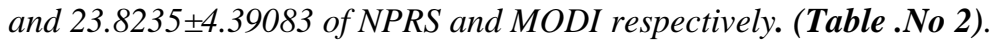

Independent sample t-test results showed that MODI of MET's and Functional task training group were 58.2 \pm 6.80 and $60.8 \pm 5.93$ respectively. As p-value for both scales were $>0.005$, therefore the data was comparable. The p value was used as <0.005 that showed that there was remarkable difference between two groups for pain and disability. (Table.No 3) 
ISSN 2201-2796

DISCUSSION:

www.scirj.org

(C) 2021, Scientific Research Journal

http://dx.doi.org/10.31364/SCIRJ/v9.i10.2021.P1021883

This publication is licensed under Creative Commons Attribution CC BY. 
Scientific Research Journal (SCIRJ), Volume IX, Issue X, October 2021

ISSN 2201-2796

This study was on Sample of $N=40$. The subjects were allocated randomly in two groups, where participants of A group received MET and participants of B group received Functional task training for a time period of 3 weeks. The rationale of this research was to compare the effects of muscles energy technique with and without functional task training. The strength of this study lies in the determination of the additive effect of functional task training along with muscle energy technique. So, with the additive effect of functional task training, the patients recovered fast as compare to the other group that received only muscle energy technique. This is supported in previous literature on SIJ management strategies $(9,15)$ Based upon the NPRS and MODI scale, this study revealed the effectiveness of both techniques. However, results of study found out the significant effect in Group B treated with functional task training along with METs and involve the precise focused on transverse abdominus and multifidus muscle. This was an agreement with the previous studies, one of which was done by Fabio Renovato (12) to determine the effect of segmental stabilization and superficial strengthening of abdominal and trunk muscles. Segmental stabilization targeted two deep muscles, transverse abdominis and multifidus, and found out the superior effects of segmental strength training. (11)while another study conducted in 2019 by Saba Muhammad to find out the effect of Muscle energy technique in SIJ dysfunction. Visual analog scale, palpation meter and doppler image of vibration were used for evaluation. This study found effectiveness of Muscle energy technique in subjects with SIJ dysfunction and proved it to be effective in treating pain and disability.(8) Javadian concluded the superior effect of segmental strengthening along with general exercise to reduce pain and disability. As weakness of the deep muscles including transverse abdominis and multifidus leads to more aggravation and recurrence of pain. So by focusing these deep muscles and target activation of both multifidus and transverse abdominis significant decrease pain and disability along with the recurrence of LBP. Although few studies had mentioned the MET's efficacy in sacroiliac joint dysfunction. The significant improvement in pain and functional limitation with the application of METS exists. The sacroiliac joint can cause pain and it also changes the biomechanics of spine and pelvis. Physical therapy, exercises, modalities and osteopathic manipulations techniques that can decrease pain and improves functional outcomes (3) The current study has used functional task training involved with use of lumbar stabilization exercises and specifically targeting the multifidus and transverse abdominis muscle on little unstable base of support..The current study has used abdominal bracing maneuver for spinal stabilization , as part of rehabilitation program of functional task training where the results showed statistically significant improvement over the MET alone group. The use of core stability which was actually the core muscle training. The $N$-30 subjects in age range of 30-45 were asked to exercise on floor with 4 types of exercise 3 times /week for 4 weeks.The outcomes tools used were VAS and ODI. The Swiss ball exercise that were used as part of stabilization of functional training of lumbar spine, were found effective in reducing low back pain with $P<.005)$. This task training involved lumbar stabilization exercises targeting the multifidus and transverse abdominis muscle on little unstable base of support, anterior and posterior pelvic tilt with heel slides, hip horizontal abduction, leg slide from crook lying position and lastly sitting and balancing on wobble board. The results showed that both groups having improvements but functional task training (Group -B) was superior with P<.005). The baseline measurements for both NPRS and MODI were comparable.

www.scirj.org

(C) 2021, Scientific Research Journal

This publication is licensed under Creative Commons Attribution CC BY. 
CONCLUSION: This study concluded that both Muscle Energy Technique and Functional Task Training were effective for treating Sacroiliac Joint Dysfunction. But Function Task Training with muscle energy technique were more effective as compare to single muscle energy technique.

\section{Participants consent and ethical consideration:}

Participants were knowledgeable about the aims \& objectives of the study was observed by all individuals and consent form in the written form was obtained. The study received approval of ethical committee of RCRS \& Allied Health Sciences. (REF\#.)

\section{Consent for research publication}

Individuals were familiar about the aims of the research and informed written statement and consent was taken.

\section{Competing interests}

There is no competing interest as declared by the author. The results of the research are obtained clearly, fairly, and without assembly, distortion, or misleading data maneuvering.

Funding Support: No any other external funding support 
References:

1. Ilaslan H, Arslan A, Koç ÖN, Dalkılıç T, Naderi S. Sacroiliac joint dysfunction. 2010.

2. Cohen SP, Chen Y, Neufeld NJ. Sacroiliac joint pain: a comprehensive review of epidemiology, diagnosis and treatment. Expert review of neurotherapeutics. 2013;13(1):99-116.

3. Arnbak B, Jensen TS, Egund N, Zejden A, Hørslev-Petersen K, Manniche C, et al. Prevalence of degenerative and spondyloarthritis-related magnetic resonance imaging findings in the spine and sacroiliac joints in patients with persistent low back pain. European radiology. 2016;26(4):1191-203.

4. FERNANDES S. COMPARATIVE EFFECTIVENESS OF MULLIGAN MOBILISATION AND MULLIGAN TAPING TECHNIQUE IN SACROILIAC JOINT DYSFUNCTION-RANDOMIZED CLINICAL TRIAL 2010.

5. Patel VD, Eapen C, Ceepee Z, Kamath R. Effect of muscle energy technique with and without strain-counterstrain technique in acute low back pain—A randomized clinical trial. Hong Kong Physiotherapy Journal. 2018;38(01):41-51.

6. Souliman S. The Role of the Physiotherapy in Treatment and Preventation of Sacroilic Joint Dysfunction. Tobruk University Journal of Medicine. 2019;2(1):70-6.

7. Alkady SME, Kamel RM, AbuTaleb E, Lasheen Y, Alshaarawy FA. EFFECT OF MUSCLE ENERGY TECHNIQUE IN CHRONIC SACROILIAC JOINT DYSFUNCTION. SVU-International Journal of Physical Therapy and Science. 2019;1(1):8-19.

8. Kaur H, Sharma M, Hazari A. Effectiveness of Maitland Mobilization and Mulligan Mobilization in Sacroiliac Joint Dysfunction: A Comparative Study. Critical Reviews ${ }^{\mathrm{TM}}$ in Physical and Rehabilitation Medicine. 2019;31(2).

9. Sharma D, Sen S. Effects of muscle energy technique on pain and disability in subjects with SI joint dysfunction. Int J Physiother Res. 2014;2(1):305-11.

10. Hwangbo G, Lee C-W, Kim S-G, Kim H-S. The effects of trunk stability exercise and a combined exercise program on pain, flexibility, and static balance in chronic low back pain patients. Journal of physical therapy science. 2015;27(4):1153-5.

11. França FR, Burke TN, Hanada ES, Marques AP. Segmental stabilization and muscular strengthening in chronic low back pain: a comparative study. Clinics. 2010;65:1013-7.

12. Javadian Y, Akbari M, Talebi G, Taghipour-Darzi M, Janmohammadi N. Influence of core stability exercise on lumbar vertebral instability in patients presented with chronic low back pain: A randomized clinical trial. Caspian journal of internal medicine. 2015;6(2):98.

www.sciri.org

(C) 2021, Scientific Research Journal

http://dx.doi.org/10.31364/SCIRJ/v9.i10.2021.P1021XX

This publication is licensed under Creative Commons Attribution CC BY. 
13. Fryer G, Pearce AJ. The effect of muscle energy technique on corticospinal and spinal reflex excitability in asymptomatic participants. Journal of bodywork and movement therapies. 2013;17(4):440-7.

14. Ramirez C, Sanchez L, Oliveira B. Prevalence of sacroiliac joint dysfunction and sacroiliac pain provocation tests in people with low back pain. Annals of Physical and Rehabilitation Medicine. 2018;61:e152.

15. Sarkar M, Goyal M, Samuel AJ. Comparing the Effectiveness of the Muscle Energy Technique and Kinesiotaping in Mechanical Sacroiliac Joint Dysfunction: A Non-blinded, Two-Group, Pretest-Posttest Randomized Clinical Trial Protocol. Asian spine journal. 2021;15(1):54. 


\section{CONSORT FLOW DIAGRAM:}

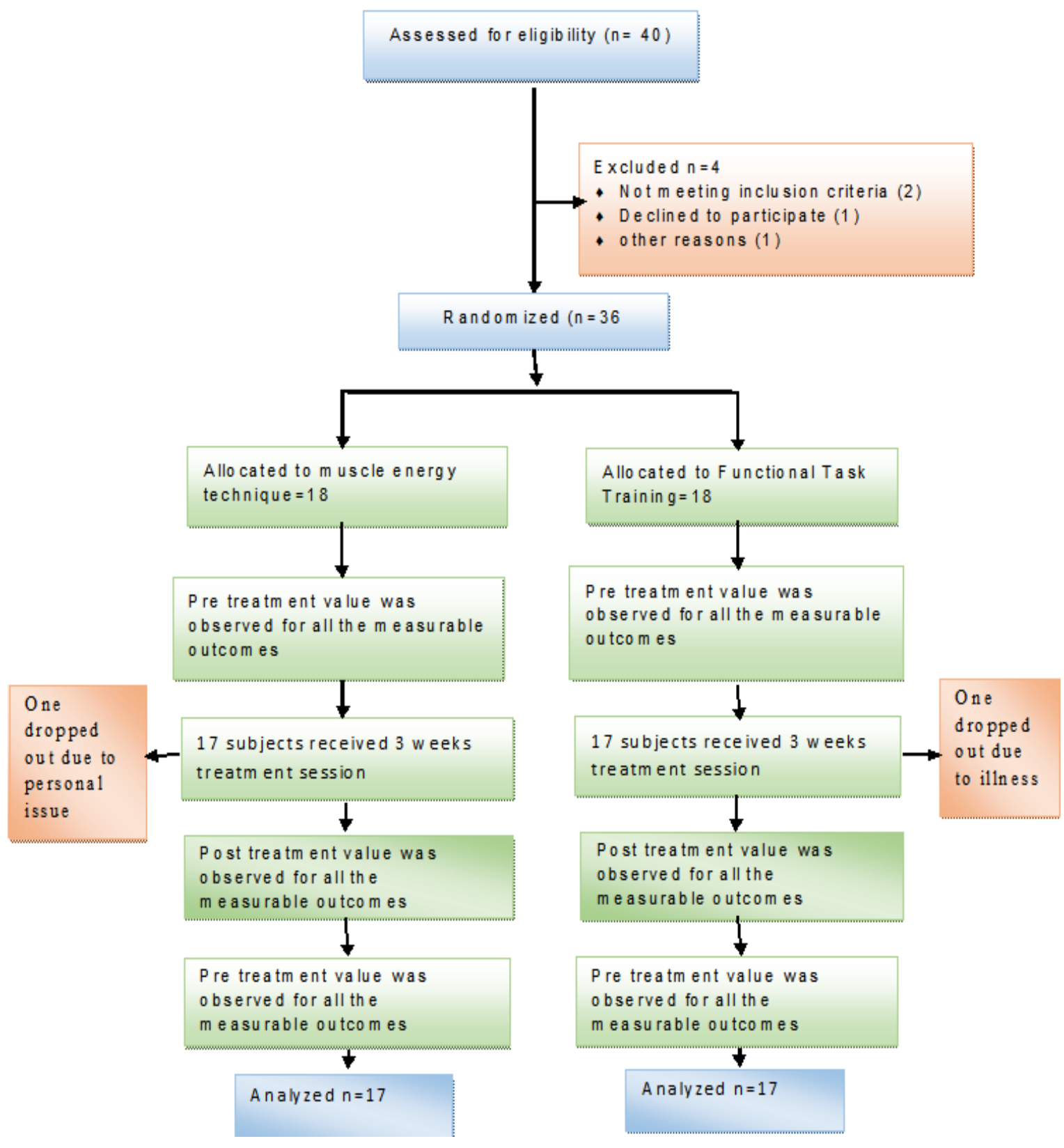

www.scirj.org

(C) 2021, Scientific Research Journal

http://dx.doi.org/10.31364/SCIRJ/v9.i10.2021.P1021XX

This publication is licensed under Creative Commons Attribution CC BY. 
Table. 1: Comparison of Socio-Demographic Variables of two Groups

\begin{tabular}{|c|c|c|c|c|c|}
\hline \multicolumn{2}{|c|}{ Study Group } & \multirow{2}{*}{$\begin{array}{l}\mathbf{N} \\
17 \\
\end{array}$} & \multirow{2}{*}{$\begin{array}{l}\text { Minimum } \\
25\end{array}$} & \multirow{2}{*}{$\begin{array}{l}\text { Maximum } \\
35\end{array}$} & \multirow{2}{*}{$\begin{array}{l}\text { Mean } \pm \text { SD } \\
29.29 \pm 3.53\end{array}$} \\
\hline \multirow[b]{4}{*}{$\begin{array}{l}n \\
\sum \\
\sum\end{array}$} & Age of Participants & & & & \\
\hline & Height in $\mathrm{m}$ & 17 & 1.49 & 1.79 & $1.619 \pm 0.090$ \\
\hline & Weight in kg & 17 & 55 & 80 & $65 \pm 6.937$ \\
\hline & Body Mass Index of Participants & 17 & 19.36 & 32.04 & $24.93 \pm 3.19$ \\
\hline \multirow{2}{*}{ 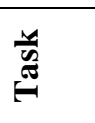 } & Age of Participants & 17 & 23 & 35 & $28.41 \pm 4.12$ \\
\hline & Height in $\mathrm{m}$ & 17 & 1.48 & 1.78 & $1.628 \pm 0.091$ \\
\hline \multirow{2}{*}{ م } & Weight in kg & 17 & 57 & 81 & $66.82 \pm 8.087$ \\
\hline & Body Mass Index of Participants & 17 & 18.31 & 30.48 & $25.53 \pm 2.56$ \\
\hline
\end{tabular}



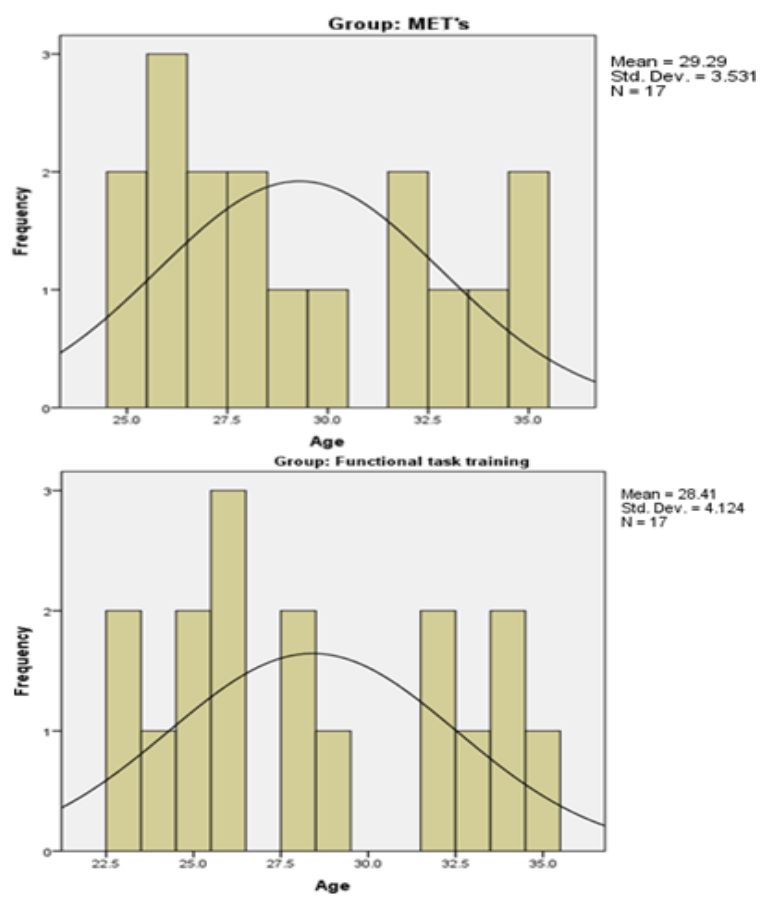

Mean $=28.41$
Sedd. Devev. $=4.124$
$N=17$

\section{Figure no.1: Histogram of Age}

The mean age of participants in muscle energy group was $29.29 \pm 3.53$ years as compare to $28.41 \pm 4.12$ years in functional task training group 


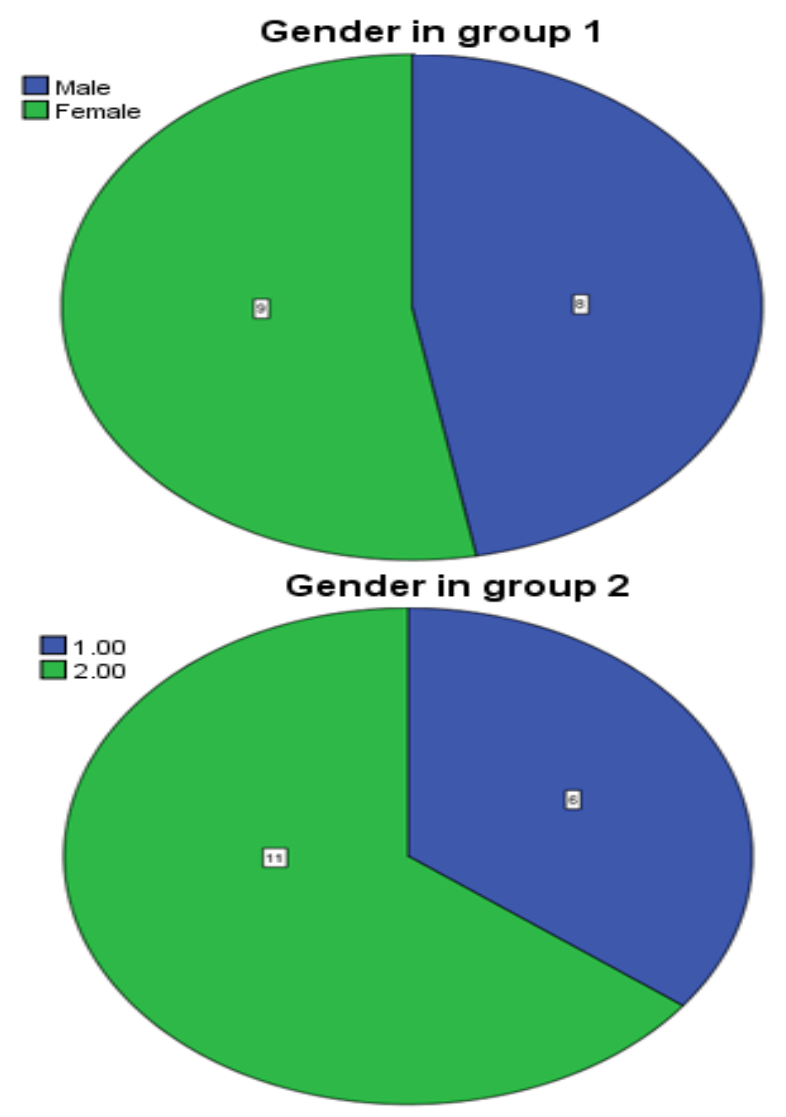

Figure No.1: Pie chart of Gender

Out of total 17 participants in each group, eight male and 9 females were included in muscle energy group as compared to 6 males and 11 females in functional task training group.

Table.2: Within group comparison of Outcomes in Both Groups

\begin{tabular}{|c|c|c|c|c|}
\hline \multirow[t]{2}{*}{ Study Groups } & & $\begin{array}{l}\text { Numeric pain rating } \\
\text { scale score (NPRS) }\end{array}$ & $\begin{array}{l}\text { Modified } \\
\text { disability } \text { Oswestry } \\
\text { (MODI) }\end{array}$ & P-Value \\
\hline & & Mean \pm SD & Mean \pm SD & \\
\hline \multirow{3}{*}{$\begin{array}{lr}\text { Muscle } & \text { Energy } \\
\text { Technique } & \text { Group } \\
\text { (MET's) } & \end{array}$} & Baseline Measurement & $7.88 \pm 1.05$ & $58.29 \pm 6.80$ & \multirow{3}{*}{0.001} \\
\hline & At the end of $1^{\text {st }}$ week & $6.5294 \pm 1.007$ & $45.0588 \pm 7.013$ & \\
\hline & At the end of $2^{\text {nd }}$ week & $5.5294 \pm 0.94$ & $35.1176 \pm 5.441$ & \\
\hline
\end{tabular}




\begin{tabular}{|l|l|l|l|l|}
\hline & Post Treatment Score & $4.7059 \pm 1.10$ & $23.8235 \pm 4.390$ & \\
\hline $\begin{array}{l}\text { Functional Task } \\
\text { Training Group }\end{array}$ & Baseline Measurement & $7.76 \pm 1.11$ & $60.88 \pm 5.93$ & \multirow{2}{*}{0.001} \\
\cline { 2 - 4 } & At the end of $1^{\text {st }}$ week & $5.2941 \pm 1.21$ & $38.6471 \pm 4.98675$ \\
\cline { 2 - 4 } & At the end of $2^{\text {nd }}$ week & $3.1176 \pm 0.69$ & $27.5882 \pm 4.21395$ & \\
\cline { 2 - 4 } & Post Treatment Score & $2.647 \pm 0.60$ & $23.8235 \pm 4.39083$ & \\
\hline
\end{tabular}


Table No. 3: Independent t-test to analyze NPRS and MODI between two Groups

\begin{tabular}{|c|c|c|c|c|c|c|}
\hline & \multirow{2}{*}{ Group } & \multirow{2}{*}{ Mean \pm SD } & \multirow{2}{*}{$\begin{array}{l}\text { Std. } \\
\text { Error } \\
\text { Mean }\end{array}$} & \multicolumn{2}{|c|}{$\begin{array}{l}\text { 95\% Confidence } \\
\text { Interval }\end{array}$} & \multirow{2}{*}{ p-value } \\
\hline & & & & lower & upper & \\
\hline \multirow{2}{*}{$\begin{array}{l}\text { Pre-Treatment } \\
\text { NPRS Score }\end{array}$} & MET's & $7.88 \pm 1.05$ & .255 & -.756 & .756 & \multirow[b]{2}{*}{1.000} \\
\hline & $\begin{array}{l}\text { Functional task } \\
\text { training }\end{array}$ & $7.76 \pm 1.11$ & .269 & -.756 & .756 & \\
\hline \multirow[t]{2}{*}{$\begin{array}{l}\text { Pre-Treatment } \\
\text { MODI Score }\end{array}$} & MET's & $58.2 \pm 6.80$ & 1.65 & -7.05 & 1.87 & \multirow[b]{2}{*}{.246} \\
\hline & $\begin{array}{l}\text { Functional task } \\
\text { training }\end{array}$ & $60.8 \pm 5.93$ & 1.43 & -7.05 & 1.87 & \\
\hline \multirow{2}{*}{$\begin{array}{l}\text { NPRS Score after } \\
\text { 1st Week }\end{array}$} & MET's & $6.52 \pm 1.01$ & .244 & .45 & 2.01 & \multirow{2}{*}{.003} \\
\hline & $\begin{array}{l}\text { Functional task } \\
\text { training }\end{array}$ & $5.29 \pm 1.21$ & .294 & .45 & 2.01 & \\
\hline \multirow{2}{*}{$\begin{array}{l}\text { MODI Score after } \\
1 \text { st Week }\end{array}$} & MET's & $45.1 \pm 7.01$ & 1.700 & 2.16 & 10.66 & \multirow{2}{*}{.004} \\
\hline & $\begin{array}{l}\text { Functional task } \\
\text { training }\end{array}$ & $38.6 \pm 4.98$ & 1.209 & 2.14 & 10.68 & \\
\hline \multirow{2}{*}{$\begin{array}{l}\text { NPRS Score after } \\
\text { 2nd Week }\end{array}$} & MET's & $5.52 \pm .943$ & .2287 & 1.83 & 2.99 & \multirow{2}{*}{.001} \\
\hline & $\begin{array}{l}\text { Functional task } \\
\text { training }\end{array}$ & $3.11 \pm .696$ & .168 & 1.83 & 2.99 & \\
\hline \multirow{2}{*}{$\begin{array}{l}\text { MODI Score after } \\
\text { 2nd Week }\end{array}$} & MET's & $35.1 \pm 5.44$ & 1.319 & 4.12 & 10.92 & \multirow{2}{*}{.001} \\
\hline & $\begin{array}{l}\text { Functional task } \\
\text { training }\end{array}$ & $27.5 \pm 4.21$ & 1.022 & 4.12 & 10.93 & \\
\hline \multirow{2}{*}{$\begin{array}{l}\text { Post Treatment } \\
\text { NPRS Score }\end{array}$} & MET's & $4.70 \pm 1.10$ & .26795 & 1.43 & 2.68 & \multirow{2}{*}{.001} \\
\hline & $\begin{array}{l}\text { Functional task } \\
\text { training }\end{array}$ & $2.64 \pm .606$ & .14706 & 1.42 & 2.68 & \\
\hline
\end{tabular}




\begin{tabular}{|l|l|l|l|l|l|l|}
\hline \multirow{2}{*}{$\begin{array}{l}\text { Post Treatment } \\
\text { MODI Score }\end{array}$} & MET's & $29.7 \pm 6.40$ & 1.55243 & 2.04 & 9.71 & \multirow{2}{*}{.004} \\
\cline { 2 - 6 } & $\begin{array}{l}\text { Functional task } \\
\text { training }\end{array}$ & $23.8 \pm 4.39$ & 1.06493 & 2.02 & 9.73 & \\
\hline
\end{tabular}


